\title{
Bringing LBC into Classroom: An Evaluation on Self-video Recorded Speaking Task Through Vietnamese Learner Perceptions
}

\author{
Phan Thi Cat Tuong ${ }^{1 *}$, Vu Phi Ho Pham² \\ ${ }^{1}$ Foreign Language Department, Ha Tinh University, Ha Tinh Province, Vietnam \\ ${ }^{2}$ Faculty of Foreign Languages, Van Lang University, Ho Chi Minh City, Vietnam \\ *Corresponding author. Email: tuong.phanthicat@htu.edu.vn
}

\begin{abstract}
Recently, thanks to the development of the Internet and other life conveniences, chances for learners to study language beyond the classroom have been expanded. Therefore, it is suggested that teachers link the world beyond the classroom (LBC) to their teaching and put their students' perceptions and experiences at the core of the teaching process. In this study, the teacher-practitioner assigned an out-of-class task in which students had to self-video record their speaking outside the classroom, but the products were then assessed in class. By using semi-structured interviews and learner reflective journals, the research draws significant evaluative findings of self-video recorded speaking task (SRST) through learner perceptions of its effectiveness and successful learning strategies. Another important finding is learner perspectives about the role of the teacher in SRST by providing input and giving feedback. Based on the findings, the study offers implications for both research and practice on SRST application within and beyond the Vietnamese context.
\end{abstract}

Keywords: Self-video Recorded Speaking Task (SRST), Language Learning and Teaching Beyond Classroom (LBC), learner perceptions, SRST effectiveness, learning strategies, teacher role.

\section{INTRODUCTION}

\subsection{Language Learning and Teaching Beyond Classroom (LBC)}

There are two dimensions of language learning: inside and outside classroom $[45,46]$. It means that beyond classroom walls, there are contexts where students can learn language on their own, or at least their learning can be supported by mediums or factors other than their classroom teachers $[1,6,7,32,41]$. While many language teachers tend to insist on their role as central to both student learning and autonomy [4, 5, 8, 24, 31, 33, 57], and consider out-of-class activities as supplementary to formal learning, there are more and more cases that students confirm their success as results of their own learning or engagement with language beyond classroom [3, 30, $40,42,43,51]$. Therefore, understanding the potential of language learning beyond classroom (lbc), thence connecting it with classroom to support both language learning and teaching, seem to become an important mission for language teachers nowadays $[39,45,47,50]$.

\subsection{Self-video Recorded Speaking Task (SRST)}

the application of video-recorded speaking task (srst), a task allowing learners to use a camera (from smartphone, laptop, or computer) to video record their own speaking out of class, has been investigated in many studies $[10,11,12,15,17,20,21,27,34$, 38]. the application of srst found in the literature usually follows this procedure: by the end of each regular speaking class, the teacher assigns a topic, then at home, students video record their speaking and post them on a private site where the teacher and other classmates could comment on. in the following class, the teacher and learners meet up to re-watch and have a deeper discussion about the videos. finally, detailed assessment and marks will be given by the teacher, either directly or via email $[2,13,18$, $29,37,38,49]$. as the procedure involves and links students working outside with inside class, srst might 
typically be a task that illustrates how teachers can link LBC to classroom learning.

\subsection{Statement of problems}

My motivation for this research stemmed from two main problems in my teaching context at ha tinh university. firstly, it was the power distance between teacher and students which restricted students' own expressions. affected by confucius culture, vietnamese teacher is usually considered as the source of knowledge. therefore, learners are accustomed to speaking only when being called. furthermore, when using the teacher as a model, students are more likely to emulate their formal speaking style rather than create their own spontaneous language. students have been generally prevented from becoming autonomous speakers in class as a result of these factors.

Secondly, it was the problematic time allocation for speaking skills at ha tinh university. since the creditbased training system was applied, the weekly speaking time in class has been reduced from 150 minutes to 50 minutes. This allocation is obviously too limited compared to the basic time requirement for students' learning and practicing language skills.

From the aforementioned issues, the idea of applying SRST was considered a spot-on solution. As SRST allows students to video-record themselves speaking outside of class, they can have more freedom in their language use, which could boost their self-confidence and autonomy in speaking. It also helps mitigate the drawback of limited time for speaking in class.

\section{LITERATURE REVIEW}

\subsection{SRST effectiveness}

SRST and its usefulness in improving learners' speaking proficiency have been studied extensively $[17,19,20,25,27,56]$. Apart from classroom teaching, students in these studies were expected to provide a weekly short video recording of themselves speaking during a fourteen-week speaking course. Students' speaking abilities and belief in this invention both improved as a result of the findings. The articles shared a number of common aspects in terms of educational context, which are also similar to the current study. First, the students were between the ages of 19 and 22, with an average of eight years of English experience. Importantly, the majority of students had no prior experience using video recording as a speaking learning tool and had a low level of speaking competence before the course.

However, there are certain discrepancies between the three parameters that may have resulted in some changes in innovation application. As the classroom education in Gromik [20] was largely grammar-based due to the japanese standard curriculum, srst was introduced to give pupils more opportunity to communicate outside of class. however, the videos were just thirty seconds long, which was obviously insufficient for a thorough analysis. with the same problem with structure-based curriculum, which was the primary culprit behind learners' speaking deficiency, srst was used to increase their proficiency by kirkgoz [27]. the distinction was that the videos were blended with task-based instruction, so video tasks were similar to class assignments, and input sources were given. furthermore, the video length in this study was three minutes, which is more appropriate, and an additional one-hour weekly session for feedback was allotted, which would be beneficial to the assessment process. gorturk [17] similarly offered three-minute video-recording tasks; nonetheless, because the participants in this research were intermediates, the evaluation appeared to be easier as students just submitted the clips to a private Facebook group, and the teacher subsequently gave individual ratings.

Some characteristics regarding the use of SRST from previous studies will be replicated in this study, including the three-minute video, fifty-minute supplementary lesson for assessing, and private Facebook group for peer feedback. Nevertheless, unlike earlier studies, the most prominent aspect in this project setting is restricted in-class time; thus, SRST that could make good use of self-study time can be an innovative feature. Additionally, whereas a majority of previous researches has focused on the improvement in participants' competency whilst overlooking the perceptual component, this research aims at learners' core beliefs as well as the perspectives impact of the self-video recorded task.

\subsection{Learning strategies regarding SRST}

Concerning learning strategies to address problems in speaking skills, findings from literature showed that srst with its distinctive features could help learners overcome some intrinsic spoken weaknesses, especially regarding accuracy and complexity. kirk got [27] recognized srst helped change students' accuracy by providing chances for students to both 
selves- and peer-review. in addition, learners praised srst for it facilitating the use of authentic lexical resources, which might help their speaking become more natural and advanced [17, 27]. The feature that SRST enables students to choose and arrange resources for their oral speeches may encourage them to use better linguistic items. Furthermore, the repeating learners made while filming videos may facilitate their retention of new vocabulary.

\subsection{Teacher role}

Another noticeable issue that emerged from previous studies is that srst was mostly considered as an extension to in-class speaking tasks through which it can help solve certain class limitations or support self-evaluation [10, 12, 15, 20, 34, 44]. there were a limited number of researches regard srst as an lbc task that can be integrated into classroom teaching with the focus on students' out-of-class learning [11, $17,38]$. additionally, most of the findings seemed to concentrate on task effectiveness [17, 20, 27, 44] while ignoring the role of the teacher. this, again, may be because srst in these contexts is seen as a supplementary speaking task to in-class teaching where the teacher role is obvious. however, if considering srst as an out-of-class learning activity that students are able to conduct on their own, with personal purposes without teacher involvement, the role of teacher in supporting and connecting srst with their teaching and making it a part of the classroom process can become a significant issue that needs to be addressed.

On the grounds of these reasons, the present study aims to investigate learner perceptions of srst effectiveness, successful learning strategies, and teacher roles. in this research, learner perceptions of the task and strategies would not only be crucial to examine its efficiency and give implications for better applications but can also provide important hints about students' learning characteristics and their own approaches in conducting the task, especially in the context beyond classroom with little or no direct help from teacher $[45,47]$. Along with these, learner perspectives about teacher roles in supporting them could also give useful indication of the position of teacher in students' LBC as well as how they can link it to classroom teaching so that they can offer more practical help to their students' learning $[45,47]$.

All due considerations, three research questions are formed:
1. What are learner perceptions on the effectiveness of SRST in improving their speaking skills?

2. What are learner perceptions on successful learning strategies regarding the application of SRST?

3. What are learner perceptions on teacher role in the application of SRST?

\section{METHODS}

\subsection{Context}

At the time of the study, the researcher was responsible for a speaking course for second-year English majors at a vietnamese tertiary institution. the expected outcomes of the course were students achieved at least 5.0 ielts speaking (equivalent to intermediate level) after freshman year and 5.5 (upper-intermediate) after sophomore year. nonetheless, 16 out of 22 students in the class did not meet the needed standard on the end-of-first-year exam, and the students' mean score was only 4.5 .

Regarding the time allotted, there was only one 50minute speaking lesson integrated with another listening one in a total of a 150-minute session a week. this was due to the university's application of a credit-based training program which required selfstudy time to triple class time. nonetheless, for this speaking program, this was a two-sided approach because it reduced half of the in-class time for practice, leaving teachers with insufficient time to examine students' classwork. furthermore, it was clear that slow learners often lost their opportunities to higher-level ones in terms of performance, and in general, students were unable to utilize all of their capabilities to finish the assignments thanks to a lack of class time.

From the aforementioned issues, the idea of applying SRST was considered a spot-on solution. The fact that SRST allows students to make videos recording their speaking out of class gives students freedom in language use, thus stimulating their self-confidence and autonomy in speaking. It also helps mitigate the drawback of limited time for speaking in class.

\subsection{Introduction of SRST}

After each speaking lesson, the teacher allocates a topic, assigns a timeframe, and recommends interesting materials. Learners had to publish their 
video recordings on classroom private Facebook before the due time so that the instructor and their peers may remark on them. Because at the end of each three weeks, student participants were given a 150-minute self-study assessment, the lecturer reallotted this into a 50-minute in-class lesson every week. during this time, the instructor and learners joined in groups to go through the clips again and analyse their strong and weak points. Following the Ielts speaking band descriptor, the instructor sent each individual their result and constructive criticism via email. In reality, over two weeks, the instructor had to assign a new stage called language input that lasted twenty minutes to class sessions before deadlines, recognizing the bewilderment of weaker learners.

\subsection{Participants}

Shaped in a qualitative study, this research only investigated 6 cases of students with three upperintermediate $(6.0$ ielts speaking) and three intermediate (4.5 ielts speaking) who were chosen from the researcher's class of 22 sophomore english teaching majors to participate in research. they were from 19 to 20 years old and had been exposed to english for eight and nine years. one upperintermediate and two intermediate participants came from the local city, while the rest were from tiny villages nearby. in this article, pseudonyms are used instead of participants' real names.

Table 1: Summary of students' biographical details.

\begin{tabular}{|c|c|c|c|c|}
\hline $\begin{array}{c}\text { Name } \\
\text { (pseudo } \\
\text { nyms) }\end{array}$ & Gender & $\begin{array}{c}\text { Age } \\
\text { (yea } \\
\text { rs) }\end{array}$ & $\begin{array}{c}\text { English } \\
\text { proficiency }\end{array}$ & $\begin{array}{c}\text { English } \\
\text { exposu } \\
\text { re } \\
\text { (years) }\end{array}$ \\
\hline Minh & Male & 19 & $\begin{array}{c}\text { Upper- } \\
\text { intermediate }\end{array}$ & 8 \\
\hline My & Female & 20 & $\begin{array}{c}\text { Upper- } \\
\text { intermediate }\end{array}$ & 9 \\
\hline Tam & Female & 19 & $\begin{array}{c}\text { Upper- } \\
\text { intermediate }\end{array}$ & 8 \\
\hline Quynh & Female & 20 & Intermediate & 9 \\
\hline
\end{tabular}

\begin{tabular}{|c|c|c|c|c|}
\hline Trang & Female & 19 & Intermediate & 8 \\
\hline Lan & Female & 19 & Intermediate & 8 \\
\hline
\end{tabular}

All of these students were familiar with the application of technology in their speaking courses, including resources available on the internet and their smartphones. however, as revealed in the interviews and journals, stronger learners had used these resources more often and effectively, while the weaker ones were not really motivated and mostly concentrated on finishing homework allocated in class in their self-study time.

\subsection{Data collection procedures}

In the present study, to collect the desired data, semistructured interviews, including individual and group interviews, were triangulated with learner reflective journals. in order to gain thorough data about the participants' perceptions, semi-structured interviews were applied [14]. as a flexible instrument that allows the raising of unscheduled follow-up queries, the use of this type of data collection could help increase the richness and validity of the data as the answers can be illustrated and analysed in detail. Following the submission of the final videos, the first and second group interviews were undertaken before six individual ones were allotted.

For the group interviews, the average time allocation was twenty minutes, while every individual one took about ten minutes. this was considered to be the most suitable for each respondent. when group interviews would enable a variety of information concerning group perceptions to be obtained, interviewing each individual can both triangulate the stated answers and investigate more insightful data, which was not emergent from group interviews due to participants' lack of confidence or avoidance of conflicts. mother tongue was recommended as it could allow the interviewees to better comprehend the queries, thus, would answer the questions more flexibly. also, the recording of the interviews was ensured to be permitted by the learners beforehand.

When the first group interview ended, each participant was asked to complete a reflective journal in which they should give their own perspectives on factors making srst affordable or not. each student 
was assigned one single day to finish the journal prior to the due of the following group interview. timeframe flexibility could have brought the respondents freedom in expressing their viewpoints. once again, the vietnamese language was stimulated as it could facilitate clearer explanation. reflective journaling is an efficient way to gain participants' underlying perspectives and beliefs, which might at times be difficult to obtain from a teacher-stance [35]. furthermore, using students' reflective journals to crosscheck the interviews was a rational option because the cognition concealed throughout potentially unpleasant direct conversations with the investigator also their professor might be expressed more openly in reflective journals.

\subsection{Data analysis}

The research's primary findings involved four categories: learner perceptions of srst effectiveness, successful learning strategies, teacher role, and "fake" fluency. the research's primary findings involved two categories: student comprehension and participation. to obtain relevant data to elucidate the important issues, two group interviews were cross-referenced with six personal ones and six journals. after data collection, fourteen datasets were transcribed and thoroughly read over. the results were then analysed using open and axial coding [55].

During the procedure of finding, underlining, and putting pre-set and emerging themes into a table, open coding was applied. to begin with, indications and appropriate quotes from specified patterns linked to the research questions were coded, which included student perspectives of srst efficacy, effective learning strategies, and the role of the instructor. further, "fake" fluency, which had been recited many times by the respondents, was discovered as an emergent theme and was explicitly coded. the patterns were then re-checked in axial coding to examine if they were actually indicative and how they have related altogether. Attributes of environment, socio-cultural setting, and associated implications that could alter the notions were evaluated at this phase.

\section{FINDINGS}

\subsection{Learner perceptions on the effectiveness of SRST in improving their speaking skills}

Participants were asked about their past learning experiences and how they considered SRST in comparison with other techniques in the first group interview. The purpose of these queries was to see how learners' educational backgrounds influenced their perceptions of SRST efficiency. With respect to the former, all respondents admitted to having minimal spoken exposure in middle school, in which they blamed their past instructors for spending the majority of practice time teaching linguistic forms, drastically reducing speaking time. Yet, when the inquiry of comparing past approaches with SRST was posed, new data arose.

I made a comparison between SRST and Mirror strategy, and she realized that the new task was useful in pointing out her faults and hence improved her self-evaluation. "The Mirror technique boosts up my courage, but I can't see my errors, while I could get it using SRST since I can playback, stop, or even speed down the clip as much as I wish." In comparison to Chatting with Natives, Tam explained that SRST "will not promote direct communication." The task, on the other hand, as she judged, was more appropriate for her level in the way that it facilitated her self-management and was beneficial for her overall skills development. "When discussing uncommon topics, I immediately got tongue twister, and our conversations had become ludicrously meaningless... SRST instilled in me a feeling of selfcontrol and helped me strengthen my speaking skills in all facets as I have well-prepared answers."

Last but not least, Minh mentioned that he had previously utilized SRST, yet this mixed model aroused his interest. Because the recordings were assessed in class and reflected by his teacher and classmates, he was able to study from his own and everyone else's strengths and weaknesses, allowing him to improve himself more effortlessly. "...Compared to the videos I created by myself before, I hardly recognized any mistake learners do; one checked them for me... I have learnt a lot from my own and especially my peers' pros and cons. I have copied a large number of my classmates' distinctive linguistic features as I know their performances were their best in order to achieve the highest scores...."

Data demonstrated that higher-level students had a thorough understanding of the core aspects and advantages of SRST. The lower-level learners, on the other hand, did not respond to this question, which might not be because they had no other technique to compare with, but might be because of their uncertainty or lack of confidence of the techniques they previously used. As lower-level students failed 
to give first perceptions of the task, another way to obtain specific details of participants' perspectives was raised, which was to elicit the benefits of SRST. Question of strengths was raised in a group, and journal records were crosschecked since they also indicated participants' recognition of their accomplishments thanks to the task.

Results showed that the six learners had varied perceptions regarding SRST effectiveness in improving their oral skills, although all of them were positive. Specifically, three low achievers noticed changes in their pronunciation. They were elated: "I am very thrilled I now talk more precisely" (Trang); "I believe now I can speak more closely to native speakers" (Lan). Quynh provided a detailed illustration: "Even though lexical richness is crucial, my foremost issue was articulation." I employed rare terms on occasion, yet nobody really identified them for my incorrect pronunciation. Rerunning videotape may assist me in efficiently self-correcting." Quynh's rationale indicated a thorough assessment of not just her personal learning but also of the approach for further development.

Improvements in sophistication were what motivated upper-intermediate learners whose correctness was not their weakness. Minh's viewpoint in the group interview, which was also agreed by the other two upper-intermediate learners, revealed: "SRST transformed our way of using advanced lexical items by giving us the opportunity to examine and select real high-quality materials." It can be seen that participants have gained positive perceptions on their accuracy and complexity improvement, and data from both kinds of learners have also shown their learning autonomy to some extent, in which they had figured out their own resolutions to the difficulties.

In general, both types of learners showed positive perceptions about SRST, which was presented through their confirmation of their improvement, especially in accuracy (pronunciation) and complexity thanks to the task as well as their preference for SRST to other techniques.

\subsection{Learner perceptions on successful learning strategies regarding the application of SRST}

A majority of data addressing the theme learner perspectives about learning strategies regarding the SRST application was coded, especially from the answers to the query: suggest ways to make the best SRST in your viewpoints. Again, higher-level students showed an obviously wider range of strategies that they believed to efficiently master the task. However, the lower-level learners also gave valuable ideas with respect to their own choices to handle SRST and develop their speaking skills in general. Because ambiguity made it difficult for intermediate respondents to provide straight feedback, an alternative method of eliciting their underpinning views was to pose personal queries.

Minh believed one of the best ways to prepare for a high-quality SRST is to use YouTube channels to search for authentic videos of the same topics than "steal" their structures and lexical resources. If not, browsing on the Internet for topic-related linguistic items can also boost up his complexity aspect. Following this tip, Minh had been praised for his smart use of language in many of his videos. Tam, on the other hand, strongly advocated subscribing to famous journals and advanced English official channels to increase her all-rounded linguistic development as well as to produce her finest videos. In her viewpoint, the famous and official sites are to be emphasized as only these sources ensure wellselected language use. Apart from the Internet, My proposed other strategies, such as joining English forums and chatting with natives, which she thought could largely facilitate her spontaneous speaking.

Three other intermediate learners also had a strong preference for YouTube; however, admitting they all needed the Subtitle button, which somewhat showed the weaknesses in their listening comprehension. Trang and Lan agreed that English language publications offered some values but admitted that they had difficulties comprehending them. Besides, Quynh suggested using mobile apps to improve her pronunciation which she asserted to be the best way to prepare for a good video.

In conclusion, with regard to successful learning strategies, both types of learners have given a thick description of their preferences of strategies to effectively handle SRST as well as improve their speaking skills in general. It can also be seen from the data that although at different levels, both strong and weaker students have shown their implicit recognition towards learning autonomy: finding their own ways to manage the task.

\subsection{Learner perceptions on teacher role in the application of SRST}

Students' cognition of the role of the teacher in the application of SRST was emerged from a number of answers, especially from the question of how they 
handled the difficulties of the task. It is clear that despite varying, the role of the teacher was deliberately recognized and praised. Particularly, in individual and group interviews, students were asked to describe their problems with SRST and what they did to manage them.

Accordingly, lower-level learners were initially worried about undertaking SRST, particularly since they heard the recordings had to be published and rated on; some uneasy feelings were shown: "I felt too nervous to look at my face and begin recording," Trang said. Such replies may highlight participants' apparent loss of self-faith, but they may also disclose the task degree of difficulty would have been beyond their capabilities, posing a threat of public embarrassment. Over two class sessions, they proved to be correct. Whereas the higher-level learners were deliberately more enthusiastic about the assignment: "I felt a little nervous upon first, however when everyone's movies were presented, I understood I achieved it" (Minh), the less capable students remained confusing: "In the first times when the teacher figured out my mistakes, I was very disconcerted" (Quynh), "I didn't think I could go on" (Lan). "I really cannot comprehend why my classmates might create such sophisticated monologues!" Trang started her perplexity. Based on the responses, it appears that SRST dissatisfied slower learners during the two initial sessions.

The instructor determined to interfere at this point. An additional language platform was implemented following her discussion with the weaker members. Consequently, lower-level students gradually adjusted their minds: "I enjoy linguistic input. Language games made it easier for me to obtain phrases for my videos" (Quynh); "It was enjoyable. I'd been expecting that for a long time" (Trang); "After the teacher assigned a new Vocabulary stage, I felt the way to deal with SRST became clearer and easier" (Lan). Not only did the data show students' positive perceptions about language input - an innovative phase that included entertaining word games but it also showed evidence of their progressive involvement in SRST thanks to instructor assistance. Although less capable learners reported interest in the linguistic input stage, advanced level students, strangely, had provided no feedback. Alternatively, they preferred the final phase, which was group discussion. The importance of instructor support was once again highlighted. I stated her positive viewpoints on the instructor's importance in offering "informative feedback and clarifications that explained every vid pros and faults." "More often than not, I thought my classmates' speech patterns were fantastic," Minh explained, "however, when you (teacher) confirmed that it wouldn't seem genuine, I was attentive." "Whenever our movies were broadcast, several flaws were exposed," Tam, the final one, applauded trainer encouraging, "yet, your sense of fun and optimism helped to reduce the tension." As can be seen in their remarks, superior students have provided explicit and substantial arguments for the lecturer's contribution. Accordingly, the instructor has patiently identified their strengths and weaknesses and assisted them in self-assessment. Despite the differences in demands between upper-intermediate participants and those lower ones, the lecturer's assistance was also appreciated for their self-development.

Data from reflective writing and individual interviews confided stronger students' reluctance to report on the language input phase. Upperintermediate learners simply admitted their indifference in individual answers because they wanted to protect their classmates' faces. "I wouldn't like the instructor placing more emphasis on simple forms," I wrote in her journal. "Everyone can look for (popular) terms and expressions themselves," Minh responded to a follow-up inquiry on why, "to produce impressive talks, we wanted complicated terminologies." Nonetheless, the stronger learners perceived that the linguistic input session was merely one in which they were uninterested, while most others were positive. According to the findings, generally, both groups of participants expressed their respect for the importance of the instructor; however the degrees differed at distinct phases.

\subsection{Emerging finding: "Fake” fluency}

An emerging finding from the data was "fake" fluency which was the most common problem confessed by both level students. Advanced learners claimed that their video speeds were always more remarkable than normal, while the intermediate ones tracked their hesitation when communicating without having prepared. They believed that the dilemma stemmed from the repetitive action they did when rehearsing for their "greatest" recordings.

\section{DISCUSSION}

Research questions were raised to investigate learners' perspectives regarding SRST effectiveness, successful learning strategies and teacher role. 
Research findings revealed that, in general, both upper-intermediate and intermediate learners had shown positive perceptions on various aspects of the task, but their cognition varied in correspondence with their competency degrees. Plus, it was apparent that lower-level learners gradually became autonomous and their interest in SRST has grown throughout time as a result of instructor support.

In the previous three decades, Richards [46] outlined how second language spoken instruction has changed from rote learning to conversational competency, and lately, to task-based instruction. Bygate's [9] ideas of the distinction between competencies and understanding, in which speaking is a skill that must be performed and practiced, illustrate this transition. It was asserted by the research participants that learners' talking time used to be severely limited due to teacher's spending extensive time on explaining forms. More crucially, the instructor's spoon-feeding approach by providing predefined frameworks could have hindered students' ability to learn independently. According to Schwarzer \& Luszczynska [53], human behavior readiness and motive situations are influenced by their perceived self-efficacy. More specifically, Yang [58] stated that students' beliefs of how oral language is learned could have a considerable impact on their selection of verbalpracticing tactics, and thus on the overall outcomes [48]. The implementation of SRST, which can alter students' beliefs from learning speaking in a passive way (which is mostly by receiving formed structures with relatively little practice in class) to practice speaking, has brought fruitful results concerning students' skills improvement.

Findings also expressed a cause-effect link between the two aspects of prior learning experiences and learner perceptions of the task. Particularly, when students had used other techniques to self-improve their oral skills before, their views and perspectives about the new task would clearly be more profound, and vice versa. Learners could make significant judgments with specific aspects on SRST as a result. The rationale behind this was that as they did not have the opportunity to communicate in school, the more capable learners began looking for ways to speak outside of class. This also explains why they were so enthusiastic about the task from the outset, believing it to be better than the existing methods. Conversely, given that inferior students had little (or no) prior experience with learning speaking on their own, they struggled to understand and become motivated in the assignment in the first place.

Although there was no comparison between SRST and other learning techniques regarding the benefits of SRST, the intermediate participants had given valuable perspectives. Accordingly, whilst using SRST, they noticed improvements in their pronouncing owing to the digital camera's playback feature and practicing time with various valuable databases. This finding was supported by Kirkgoz [27], who found that SRST enhanced learners' accuracy. Furthermore, upper-level learners praised SRST for facilitating the usage of relevant actual resources, which could enable them to use more sophisticated expressions - a finding in tune with Kirkgoz [27] and Gorkturk [17].

The favorable outcomes may not only have come from the task's distinctive qualities but also from other supporting variables. Firstly, the digital camera's peculiar self-reflective feature, which allows users to replay, could assist learners in properly assessing their skills. Secondly, in addition to offering students more flexibility in selecting materials, SRST was paired with linguistic input, constructive debate, and instructor evaluations when used as a teaching strategy, resulting in holistic support for student learning. Furthermore, motivating policy regarding ICT advocating technology use in pedagogy at Ha Tinh University were preconditions for the adoption of the SRST. Most significantly, learning autonomy was increasingly recognized and acquired by the learners.

The students' gradual improvement of their autonomy towards doing SRST was a good signal in a scenario where the teacher-centered model had previously influenced them. Both strong and weaker learners have demonstrated a high degree of autonomy while finding their own solutions to the challenges when undertaking SRST. However, initially, higher-level students showed better understanding, and therefore, higher favor on the task. This might be driven by the fact that they have different learning techniques. In terms of educational histories, having limited previous spoken practice in high school may have an adverse on learners' verbal capabilities, particularly after they entered postsecondary schooling [52]. Upper-intermediate learners, on the other hand, were more self-determined and became acquainted with practicing oral skills by themselves and hence may be more inspired to implement the task. It could be argued that the more independently participants engaged in SRST, the more vividly they may perceive the technique's strengths and weaknesses, therefore the more effectively they would apply it. It can be said that learning autonomy might be the most important aspect of SRST as participants were expected to learn independently almost all the time, and instructor lecturing time was restricted to roughly 30 minutes per week. Being autonomous may have 
influenced learners' beliefs on SRST values, which may have benefited their learning as a result [22, 23].

While student autonomy was vital in SRST operation, instructor assistance was also essential as the task required constructive feedback. Together with functioning as a challenger forcing participants to gain knowledge, trace for errors, and come up with clarifications on their own, the instructor in SRST also acted as a booster to students by always being present when they needed help [36]. In this case, effective teaching could be a key driver behind slower students' improved perceptions of the task. When the instructor realized their disinterest was due to their lack of confidence, she welcomed them when making errors and offered them techniques to solve them. In addition, for weaker learners, additional "simple" lexical quizzes and extensive clarifications of vocabulary utilizations were presented in class. As a result, they were able to perceive and afford the assignment more easily. Better respondents, on the other hand, acknowledged their disinterest in this extra phase, which can be explained by proficiency variations between different levels with distinct requirements and emphases. This proposed that the modifications be reconsidered and that the instructor seek for strategies to match diverse demands in a mixed-level class. However, this does not imply that upper-level students did not value the instructor's assistance.

The findings demonstrate their optimistic perception during the negotiation stage, in which the instructor's critical responses were fundamental to their progress. This result echoed Kim's [26] findings, which showed that adopting a filming technology under instructor direction aided trainees' verbal performance. Skinner and Belmont [54] and Klem and Connell [28] findings examined the association between instructor facilitation and learner perspectives backed up this conclusion.

Finally, "false" fluency was identified as the most noticeable SRST problem. It was supposed that since they wanted to release "flawless" recordings, students tried to practice and repeat talks. This characteristic of SRST has the potential to make repetitive studying a routine for learners, resulting in "false" fluency. In particular, they can only communicate effectively when they use the same terminology or discuss the same issues. Nevertheless, one of the declared goals of using SRST in this setting was to address the participants' lack of complexity. It was the reason for memorization to be considered agreeable, mostly for vocabulary mastery. The research's "rush" mode can also be an additional source of "fake" fluency. It only prolonged six weeks, which was insufficient time to see any significant effects. As an innovation, it takes time to establish and then discover solutions to issues detected. Thus, together with their own strategies and the instructor's usage of certain other fluencyfacilitating approaches, learners should adhere to SRST and apply it to its maximum potential in order to improve their spoken accuracy and intricacy.

\section{CONCLUSION}

This study applied a qualitative evaluative study of SRST as an out-of-class speaking task in a Vietnamese tertiary context. Our analysis aimed at indicating learner perceptions regarding task effectiveness, successful learning strategies and teacher roles in the task application. In this way, the study can contribute to LBC literature in painting out a part of the world beyond the classroom where students can learn language on their own. More importantly, it also highlights implications about how teacher needs to understand that world, reconsider their roles, and search for ways to link it to the classroom in order to better support their students' learning. It could be claimed that SRST was used not just to satisfy the personal interests of the teacherpractitioner but also to meet the educational demands of learners. It was a scarcity of a technique that would allow them to develop speaking outside of school. As a result, SRST has proven to be a valuable and appealing tool for learners' spoken practice.

Much still needs to be undertaken, though, as issues have emerged all through the procedure. To begin with, instructor modifications will be required in the near future to harmonize degrees of difficulty within the linguistic input phase in order to meet the demands of various learners. Ten minutes will be set out for intermediary vocabulary games, whilst remaining time will be used to clarify more sophisticated idioms to upper-intermediates. Moreover, to tackle the problem, which is slower learners continue to struggle with content preparation, the instructor will create a separate Facebook group where she will be able to provide the necessary instruction and prompt responses to their inquiries. Another issue was "false" fluency, which would be addressed by the implementation of postspeaking exercises in the classroom. Role-playing, direct interaction and discussion, interviewing, or debating events can assist learners in revising the assignment in dissimilar ways, which can enable them to not only recall language characteristics but also improve their two-way communication and actual fluency.

Concerning the research procedure, given that the research was carried over a short period of time in a 
regular classroom, qualitative methodology was applied. This data inquiry was deemed appropriate for the present research, for its goal was to examine student perspectives. Participants' insights, including their underlying perceptions, comprehension, and interests, might have been acquired and properly examined using a qualitative approach. Two group interviews and six individual ones were combined with six reflective diaries to provide fourteen datasets that could be suitable for data analyses. Instrument triangulation would allow data regularities and concurrences to be obtained, and by the ability to cross-check evidence from several sources, the reliability of the results can be ensured. Furthermore, inherent limitations or biases of a single approach might be lessened or avoided by combining different methodologies, which ultimately could increase study validity.

Respondents' perceptions of SRST were acquired using three method tools. The manner pupils responded to the inquiries might reflect how much they enjoyed the project. Reflective journals were used to collect particular facts and illustrations of how the task worked or not for each participant. Furthermore, a variety of data regarding learner perspectives on SRST was yielded in group interviews. Individual follow-up queries were generated as a result of this. Learners' difficulties, on the other hand, may well be confessed individually rather than in groups. Consequently, individual interviews appeared to provide more comprehensive data than group ones.

Besides, throughout data collection, concerns with diaries and the second group interview were also raised. First and foremost, since the second group interview's query was close to that of journals, almost all of the viewpoints were disclosed when they were given prior to it. Thus, the second group interview appeared to be unnecessary. Moreover, when it came to the journal, the researcher made an error by not ensuring respondents' identities were kept secret; as a result, the journal's effectiveness tended to be diminished because it was mostly nothing distinct from an individual interview. At the same time, certain individuals may find it far easier to explain themselves simply in a live questioning manner.

Furthermore, distinctive socio-cultural characteristics may have an impact on data gathering, particularly in group interviews. The threat of losing face or conflict avoiding may have been the driving factor for a majority of data from lower-level students was only gained through individual questions. Likewise, the intent to preserve their classmates' faces was the reason why the stronger learners' opposition with the lexical input phase was only disclosed until individual inquiries. Such realities highlighted the significance of instrument triangulation, yet more crucially, if this study could be replicated, it might necessitate a modification of equipment. There should be merely one group interview, and as a substitute to the diary account, the observation that enables the instructor to immediately and practically observe students' learning in class would be crossreferenced. As observation allows the instructor to double-check evidence, it may also improve the reliability of the data.

Performing dual responsibilities could allow the teacher-researcher to fully immerse herself in the setting, obtain a greater grasp of the investigated subject and respondents, as well as reduce "red tape" in acquiring consent from them. Nonetheless, an "internal" investigator may lose impartiality as a result of undue influence and inherent biases. In fact, when expressing their thoughts about their own instructor's teaching, learners are highly prone to hide some truthful thoughts or discontent. Furthermore, being an insider, the instructor may be more likely to overlook the privacy and sensitivities of data in data processing or be inadvertently ignorant to possibly crucial evidence.

Despite the fact that doing research to evaluate teacher practitioners' own instruction was a difficult task, it was a beneficial experience. Being a greenhorn researcher could also imply undertaking all of the demanding work from comprehensively studying the literature, attracting the attention of learners, dealing with ethical difficulties, and gathering and evaluating data. Most of the sustained effort, though, appeared to yield fruitful outcomes. The results not only provided suggestions for improving the instructor's future teaching, but they also offered a reflection on what she had accomplished which can generate an underlying incentive. As an educator, it seems that adopting the most effective techniques is the greatest approach for her to show her concern for her learners, and thus, becoming a researcher probably is the best option to achieve that goal.

Examining her own methods not only allowed the teacher-practitioner to evaluate and enhance her teaching, but it also helped her develop a deeper knowledge of her learners, allowing her to provide concrete solutions to aid their learning. Regarding this project, being a researcher benefited the instructor in diagnosing SRST challenges and learner struggles in a more explicit and comprehensive manner. Therefore, by employing suitable data collecting tools, particularly within the qualitative 
inquiry, the practitioner was able to acquire an insightful understanding of learners' cognition, allowing them to focus on crucial events and the reasoning that underpins them. In addition, relevant literature and distinctive socio-cultural characteristics were thoroughly examined. All of this could aid the instructor in addressing the emergent issues in a logical and appropriate way.

By undertaking research, the instructor draws a valuable lesson that affirmed Delpit's [16] statement that the educator should not be the sole master of the class. Professors should consider learners' perspectives in order to become competent teachers, content drivers, and administrators of their own instruction. Only by placing learners at the heart of each instructional procedure and prioritizing their engagement and development can teaching become a worthwhile profession.

\section{AUTHORS' CONTRIBUTIONS}

Phan Thi Cat Tuong is responsible for data collection and analysis. she has also conducted a broad review of related literature and completed the paper. Pham Vu Phi Ho is responsible for counseling and editing stages.

\section{ACKNOWLEDGMENTS}

The authors of this paper acknowledged the help of the faculty of foreign languages and the students of Ha Tinh University. Their supports was valuable to make this project complete.

\section{REFERENCES}

[1] Ahmed, R., In Al-kadi, A., In Hagar, T., \& IGI Global, Enhancements and limitations to ICTbased informal language learning, 2020.

[2] Bailly, S., Teenagers learning languages out of school: what, why and how do they learn? How can the school help them? In Beyond the language classroom, Palgrave Macmillan, London, 2011, pp. 119-131.

[3] Barkhuizen, G., Home Tutor Cognitions and the Nature of Tutor-Learner Relationships, In Beyond the language classroom, Palgrave Macmillan, London, 2011, pp. 161-174.

[4] Benson, P., Teachers' and learners' perspectives on autonomy. In T. Lamb \& H. Reinders (Eds.), Learner and teacher autonomy: Concepts, realities and responses, Amsterdam: John Benjamins, 2008, pp. 15-32.
[5] Benson, P., Making sense of autonomy in language learning, In R. Pemberton, S.

Toogood, \& A. Barfield (Eds.), Maintaining control: Autonomy and language learning, Hong Kong: Hong Kong University Press, 2009, pp. 13-26.

http://dx.doi.org/10.5790/hongkong/9789622099 234.003.0002.

[6] Benson, P., Language learning and teaching beyond the classroom: An introduction to the field, In P. Benson \& H. Reinders (eds.), 2011, pp. 7-16.

[7] Benson, P. \& H. Reinders (eds.), Beyond the language classroom, Basingstoke: Palgrave Macmillan, 2011.

[8] Breen, M.P. \& Mann, S.J., Shooting arrows at the sun: Perspectives on a pedagogy for autonomy, In Autonomy and Independence in Language Learning, P. Benson \& P. Voller (eds), Harlow: Addison Wesley Longman, 1997, pp. 132-149.

[9] Bygate, M. Speaking, Oxford: Oxford University Press, 1987.

[10] Castañeda, M., \& Rodríguez-González, E., L2 speaking self-ability perceptions through multiple video speech drafts, Hispania, 94(3), 2011, pp. 483-501.

[11] Chee SL., Finding activities that engage learners, In Richards JC (ed.) Key Issues in Language Teaching, Cambridge: Cambridge University Press, 2015, pp. 652-653.

[12] Cheng, G., \& Chau, J., Digital video for fostering self - reflection in an ePortfolio environment, Learning, Media and Technology, 34(4), 2009, pp. 337-350, DOI:10.1080/17439880903338614.

[13] Chern, C. L. \& K. Dooley, Learning English by walking down the street, ELT Journal 68.2, 2014, pp. 113-123.

[14] Dahlberg, L. \& McCaig. C. (2010). Practical Research and Evaluation: A start to finish guide for practitioners. Sage: Los Angeles.

[15] Danny Huang, H. T., \& Alan Hung, S. T., Implementing electronic speaking portfolios: Perceptions of EFL students. British Journal of Educational Technology, 41(5), 2010, pp. 8488. 
[16] Delpit, L., The silenced dialogue: Power and pedagogy in educating other people's children, Harvard educational review, 58(3), 1998, pp. 280-299.

[17] Göktürk, N., Examining the Effectiveness of Digital Video Recordings on Oral Performance of EFL Learners. Teaching English with Technology, 16(2), 2016, pp. 71-96.

[18] Grode, J., \& Stacy, A., Authentic Materials and Project-Based Learning: In Pursuit of Accuracy, In Language Learning Beyond the Classroom, Routledge, 2015, pp. 187-195.

[19] Gromik, N., Producing cell phone video diaries, In M. Thomas (Ed.), Handbook of research on Web 2.0 and language learning. Hershey (PA): Information Science Reference, 2009.

[20] Gromik, N. A., Cell phone video recording feature as a language learning tool: A case study, Computers \& Education, 58(1), 2011, pp. 223-230.

[21] Hafner, C. A., \& Miller, L., Fostering learner autonomy in English for science: A collaborative digital video project in a technological learning environment, Language Learning \& Technology, 15(3), 2011, pp. 68-86.

[22] Ho, Y. K., Audiotaped dialogue journals: An alternative form of speaking practice, ELT Journal, 57(3), 2003, pp. 269-277.

[23] Hsu, H. Y., Wang, S. K., \& Comac, L., Using audio blogs to assist English-language learning: An investigation into student perception, Computer Assisted Language Learning, 21(2), 2008, pp. 181-198.

[24] Hurd, S., Beaven, T., \& Ortega, A., Developing autonomy in a distance language learning context: Issues and dilemmas for course writers, System, 29(3), 2001, pp. 341-355.

[25] Kiernan, P. J., \& Aizawa, K., Cell phones in task-based learning: are cell phones useful language learning tools? ReCALL, 16(1), 2004, pp. 71-84.

[26] Kim, S. H., Developing autonomous learning for oral proficiency using digital storytelling, Language Learning \& Technology, 18(2), 2014, pp. 20-35. Retrieved from http://ltt.msu.edu/issues/june2014/action1.pdf

[27] Kirkgoz, Y., A blended learning study on implementing video recorded speaking tasks in task-based classroom instruction, TOJET: The Turkish Online Journal of Educational Technology, 10(4), 2011.

[28] Klem, A. M., \& Connell, J. P., Relationships matter: Linking teacher support to student engagement and achievement. Journal of school health, 74(7), 2004, pp. 262-273.

[29] Knox, J., Foreign eyes on Thailand: An ESP project for EFL learners, In A. Burns \& H. da Silva Joyce (eds.), Planning and teaching creatively in a required curriculum for adult learners, Alexandria, VA: TESOL, 2007, pp. 119-142.

[30] Kozar, O., \& Sweller, N., An exploratory study of demographics, goals and expectations of private online language learners in Russia, System, 45, 2014, pp. 39-51.

[31] La Ganza, W., Learner autonomy-teacher autonomy, Learner and teacher autonomy: Concepts, realities and responses, 2008, pp. 6379.

[32] Lai, C., Autonomous language learning with technology: Beyond the classroom, Bloomsbury Publishing, 2017.

[33] Little, D., Learning as dialogue: The dependence of learner autonomy on teacher autonomy, System, 23(2), 1995, pp. 175-181.

[34] López, enrique vez, \& Bertani, T. V., The impact of self-video recordings in raising oral production, Matices En Lenguas Extranjeras, (11), 2017, pp. 76-101.

[35] Mackey, A., \& Gass, S. M., Second language research: Methodology and design. Routledge, 2015.

[36] Mariani, L., Teacher support and teacher challenge in promoting learner autonomy, Perspectives: A Journal of TESOL Italy, XXIII (2), 1997. Retrieved from http://www.learningpaths.org/papers/papersuppo rt. htm.

[37] Mercado, L. A., Integrating classroom learning and autonomous learning, Language learning beyond the classroom, 2015, pp. 190-201.

[38] Miller, L., \& HAFNER, C., Taking control: A digital video project for English for science students, In Language learning beyond the classroom (pp. 212-222), Routledge, 2014. 
[39] Mynard, J. \& L. Carson (eds.), Advising in language learning: Dialogue, tools and context, Harlow: Longman, 2012.

[40] Nunan, D., Language teaching methodology, London: Prentice Hall, 1991.

[41] Nunan, D., \& Richards, J. C. (Eds.), Language learning beyond the classroom. Routledge, 2015.

[42] Pickard, N., Out-of-class language learning strategies: Three case studies, Language Learning Journal, 12, 1995, pp. 35-37.

[43] Points C, Shimazumi M, Learning-to-learn with ourselves and with our peers through technology, In: Nunan D, Richards JC (eds) Language Learning Beyond the Classroom, New York: Routledge, 2014.

[44] Putri, R. N., \& Rahmani, B. D., Students Perception on Using Video Recording to Improve Their Speaking Accuracy and Fluency, In UICELL Conference Proceeding (pp. 113122), 2019.

[45] Reinders, H., \& Benson, P., Research agenda: Language learning beyond the classroom, Language Teaching, 50(4), 2017, pp. 561-578.

[46] Richards, J., Thirty years of TEFL/TESL: A personal reflection. RELC Journal, 33 (2), 2002, pp. 1-35.

[47] Richards, J., The changing face of language learning: Learning beyond the classroom, RELC606 Journal 46.1, 2015, pp. 5-22.

[48] Rossum, E. V., \& Schenk, S. M., The relationship between learning conception, study strategy and learning outcome, British Journal of Educational Psychology, 54(1), 1984, pp. 73-83.

[49] Rowland, L., The pedagogical benefits of a linguistic landscape project in Japan, International Journal of Bilingual Education \& Bilingualism 16.4, 2013, pp. 494-505.

[50] Rubin, J., Reflections on the good language learner. In C. Griffiths (ed.), Lessons from the good language learner, Cambridge: Cambridge University Press, 2008, pp. 10-15.

[51] Sasaki A, E-mail tandem language learning, In: Nunan D, Richards JC (eds) Language Learning Beyond the Classroom, New York: Routledge, 2014.

[52] Sawir, E., Language difficulties of international students in Australia: The effects of prior learning experience, International Education Journal, 6(5), 2005, pp. 567-580.

[53] Schwarzer, R. \& Luszczynska, A., Social cognitive theory, Predicting health behavior, 2, 2005, pp. 127-169.

[54] Skinner, E. A., \& Belmont, M. J., Motivation in the classroom: Reciprocal effects of teacher behaviour and student engagement across the school year. Journal of educational psychology, 85(4), 571, 1993.

[55] Strauss, A.L. and Corbin, J., Basics of Qualitative Research (2nd edn 1998; $3^{\text {rd }}$ edn 2008), London: SAGE, 1990.

[56] Thornton, P., \& Houser, C., Using mobile phones in English education in Japan, Journal of Computer Assisted Learning, 21, 2005, pp. $217-$ 228.

[57] Voller, P. (eds.), Autonomy and Independence in Language Learning, London: Longman, 1997.

[58] Yang, N. D., The relationship between EFL learners' beliefs and learning strategy use, System, 27(4), 1999, pp. 515-535. 